\title{
Erratum to: New Molecular Wires with Two Ferrocene Hinges
}

\author{
Jingxiang Ma $\cdot$ Marc Vollmann $\cdot$ Henning Menzel $\cdot$ \\ Sven Pohle $\cdot$ Holger Butenschön
}

Published online: 5 October 2012

(c) Springer Science+Business Media New York 2012

Erratum to: J Inorg Organomet Polym (2008) 18:41-50

DOI 10.1007/s10904-007-9189-1

The following is a correction in the original publication:

The ${ }^{1} \mathrm{H}$ NMR and HRMS data reported for compound $\mathbf{1 7}$ are incorrect. The correct data are ${ }^{1} \mathrm{H}$ NMR $\left(\mathrm{CDCl}_{3}, 400\right.$ $\mathrm{MHz}): \delta=1.30(\mathrm{~s}, 9 \mathrm{H}, \mathrm{tBu}), 4.24+4.28(2 \times 2 \mathrm{H}, \mathrm{FcH})$, $4.45+4.47(2 \times 2 \mathrm{H}, \mathrm{FcH}), 7.46+7.49\left(\mathrm{AA}^{\prime} \mathrm{BB}^{\prime}, 4 \mathrm{H}\right)$; HRMS $\left(\mathrm{C}_{22} \mathrm{H}_{21} \mathrm{FeIS}\right)$ : calcd., 499.9758, found, 499.9750.

We apologize for any inconvenience and thank Dipl.Chem. Nico Krausse for providing the correct data.

The online version of the original article can be found under doi:10.1007/s10904-007-9189-1.

J. Ma $\cdot$ M. Vollmann $\cdot$ H. Butenschön $(\bowtie)$

Institut für Organische Chemie, Leibniz Universität Hannover,

Schneiderberg 1B, 30167 Hannover, Germany

e-mail: holger.butenschoen@mbox.oci.uni-hannover.de

H. Menzel · S. Pohle

Institut für Technische Chemie, Technische Universität

Braunschweig, Hans-Sommer-Straße 10, 38106 Braunschweig,

Germany 